\title{
S-N CURVE AND QUANTITATIVE RELATIONSHIP OF SINGLE-SPOT AND MULTI-SPOT WELDINGS
}

\author{
Yang, L.; Yang, B.; Yang, G. W.\#; Xiao, S. N.; Zhu, T. \& Wang, F. \\ State Key Laboratory of Traction Power, Southwest Jiaotong University, Chengdu, 610031, China \\ E-Mail: gwyang@home.swjtu.edu.cn ( ${ }^{\#}$ Corresponding author)
}

\begin{abstract}
The relevant $\Delta F-N$ curves are fitted based on the experimental life and load of single-spot and multispot-welded specimens. To improve the correlation and universality of curves, a unified S-N curve is needed. The finite element model of spot welding is firstly established. The S-N curves of single-spot and multi-spot-welded specimens are thereafter obtained according to the fatigue life of spot-welded specimens and the corresponding equivalent structural stress calculated based on the Sheppard method. To improve the fitting effects of S-N curves with relatively low correlation coefficients, the structural stress formulae are optimized using three different optimization methods based on the quasi-Newton method. Finally, the quantitative relationship among the S-N curves of spot welding with different solder joints is deduced; the foregoing can provide reference for the prediction of fatigue life of multi-spot welding.

(Received in February 2020, accepted in July 2020. This paper was with the authors 4 months for 1 revision.)
\end{abstract}

Key Words: Spot Welding, Quantitative Relationship, S-N Curve, Finite Element Method, Optimization

\section{INTRODUCTION}

Spot welding is an important method especially used for locomotive, subway, and automobile bodies to join stainless steel sheets [1]. Among its advantages are short heating time, fast welding speed, and low production cost. Stainless steel is widely used in rail transit and automobile industries because of its high strength, high hardness, high resistivity, and low thermal conductivity. Stainless steel bodies are thus typically joined by spot welding. Generally, the automotive body have 8.000-12.000 solder joints and stainless steel body of rail vehicles have up to 50.000 solder joints [2]. However, welding defects such as poor sidewall fusion, overlap, gas pore and slag inclusion are easy to occur during the process of spot welding [3].The reliability of spot welding is therefore essential to guarantee that the locomotive vehicle is safe, stable, and affords comfort.

Currently, the research related to the fatigue strength of spot-welded joints is based on fatigue experiments and complex finite element models. The $\Delta F-N$ curves can be obtained from fatigue experiments. However, the $\Delta F-N$ curves vary with the input parameters, i.e., load mode, plate thickness, and weld nugget diameter in the experiments. The process is time-consuming, laborious, and uneconomical if the experimental research is performed for each form, thus limiting the engineering application of spot welding. In order to correctly predict and evaluate the fatigue life of spot welding, it is therefore necessary to establish a method that can accurately express its fatigue characteristics, which have theoretical significance and engineering value.

The fatigue problem of spot welding has been investigated by several experts and scholars. The relatively classic fatigue evaluation methods of spot welding include Sheppard method [4, 5], Rupp method [6], Swellam method [7, 8], and Kang method [9]. Among these, both Sheppard and Rupp methods are widely used in engineering. Pan and Sheppard [10] found that even under relatively low loads, significant yielding would occur in the spot-welded joint. They accordingly proposed a method to predict the fatigue life of spot welding using strain. Based on the foregoing research, Lee and Choi [11] verified that a single J-integral cannot adequately 
describe the relationship between the loads and fatigue life of spot-welded specimens. They accordingly obtained another effective parameter, i.e., $J_{e}$, based on the $\mathrm{J}_{\mathrm{I}}, \mathrm{J}_{\mathrm{II}}$, and $\mathrm{J}_{\mathrm{III}}$ integrals and proposed a comprehensive method to predict the fatigue life of spot-welded specimens that is independent of the geometry and load types. Later, Kang [9] proposed a method based on the Rupp method [6], where the stress component of the von Mises equation was substituted into the local structural stress near the spot welding. The structural stress at the spot weld nugget was then calculated based on the force and moment obtained from finite element analysis. This method is widely used because it can better predict the fatigue life of spot welding. In addition, BP neural network method [12], formula for fatigue damage and life estimation [13], and fatigue life prediction model [14] are widely used in the fatigue assessment of multi-spot welding.

The above research works have considerable contributions related to fatigue life prediction method, crack growth mechanism, finite element simulation of spot welded specimens, and variable amplitude loading experiment of two-spot welding. Certain deficiencies related to the accurate representation of fatigue characteristics of spot welding, prediction and evaluation of fatigue life of multi-spot welding, and obtainment of the quantitative relationship between single-spot and multi-spot weldings, however, still remain. A unified fatigue characteristic curve ( $\mathrm{S}-\mathrm{N}$ curve) and quantitative relationship curve of single-spot and multi-spot weldings are therefore necessary to predict the fatigue life of spot-welded structures.

In this study, the S-N curves of spot-welded specimens are investigated based on the Sheppard method by utilizing the fatigue test data obtained from single-spot-welded specimens and the data of multi-spot-welded specimens found in related references. Spot welding S-N curves with low correlations are optimized. Finally, the quantitative relationship between the fatigue life of single-spot and multi-spot weldings is determined, thus making this study more significant.

\section{THEORY AND EXPERIMENT}

\subsection{Fatigue evaluation method}

The Sheppard evaluation method $[4,5,15]$ considers that the structural stress of spot welding is related to the crack propagation life obtained by linear elastic fracture mechanics. This method establishes the fatigue crack propagation model of the spot-welded joint and estimates the fatigue life of spot welding through the relationship between structural stress and life. It has a wide scope of applications and good prediction capability. In this study, the Sheppard evaluation method $[4,5,15]$ is used for the spot welding fatigue evaluation; the structural stress is as expressed by Eqs. (1) to (4):

$$
\begin{gathered}
\Delta S=\sigma_{\max }(Q)+\sigma_{\max }(M)+\sigma_{\max }(P) \\
\sigma_{\max }(Q)=\frac{\Delta Q}{s \omega} \\
\sigma_{\max }(M)=\frac{6 \Delta M^{*}}{s^{2} W} \\
\sigma_{\max }(P)=\frac{\Delta P}{s^{2}}
\end{gathered}
$$

where $\Delta Q / s \omega$ is the membrane stress term; $6 \Delta M^{*} / s^{2} W$ is the bending stress term; $\Delta P / s^{2}$ is the axial stress at the edge of the weld nugget induced by axial load; $s$ is the specimen thickness; $\omega=\pi d / 3$ is the effective width of the section over which the shear force acts; $d$ is the nugget diameter; $W$ is the width of the specimen. According to references $[8,16]$, the determination of $\Delta M^{*}$ is based on the nodal force conditions and moment ranges at spot-welded connections.

The shell and beam elements are used to establish the finite element model of the spotwelded joint, and the force and moment are obtained at the weld nugget by simulation in the 
evaluation method. Finally, $\Delta Q, \Delta M^{*}$, and $\Delta P$ are determined according to the force and moment ranges. Sheppard $[4,5,15]$ assumed that the crack propagation life was equal to the total fatigue life of the spot welding. An equation obtained by curve fitting was then derived from a plot of maximum structural stress range $\left(\Delta S_{\max }\right)$ versus measured fatigue life $\left(\Delta N_{f} /(1-R)\right)$ on a log-log scale as follows:

$$
N_{f}=C \frac{1-R}{\left(\Delta S_{\max }\right)^{b}}
$$

where $N_{\mathrm{f}}$ is the total life spent in propagating the crack through the sheet thickness; $R$ is the load ratio $\left(P_{\min } / P_{\max }\right)$. The coefficient $(C)$ and exponent $(b)$ are from a power law relationship of maximum structural stress range versus measured fatigue life for crack propagation.

\subsection{Experiment}

Stainless steel is a type of alloy steel that can be categorized into austenite, martensite, and ferritic according to the elements contained and components of each part [17]. The spot-welded specimens investigated in this research are made of the most widely used austenitic stainless steels. Specifically, the 1.4318 austenitic stainless steel in EN10088-2:2005 [18] is used as the base metal for spot-welded specimens. Fatigue experiments on single-spot welded specimens subjected to tensile and shear loads are performed. The single-spot welded specimens in the experiments have different plate thicknesses and welding nugget diameters. All experiments are performed on the RUMUL high-frequency fatigue tester in Switzerland, as shown in Fig. 1.

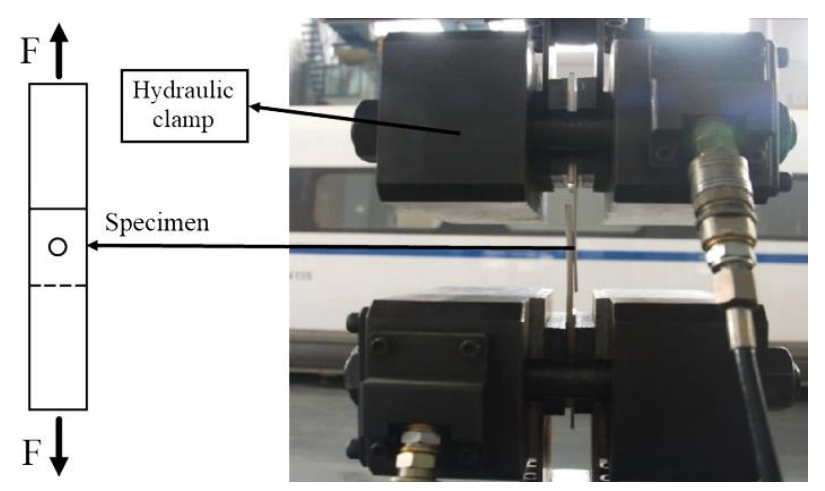

Figure 1: Schematic of hydraulic clamp and specimen installation.

Many experts and scholars have conducted a large number of fatigue tests on multi-spotwelded specimens under tensile and shear loads. In this study, the data of fatigue life of multispot-welded specimens are obtained from references [12-14, 19-28]. The referred experiment life values of tensile-shear fatigue experiments on multi-spot-welded specimens are expressed in the form of Figs. 6 and 7. According to the number of solder joints, the multi-spot-welded specimens can be divided into two, three, and four solder joint types. The diagrams of singlespot and multi-spot-welded specimens are shown in Fig. 2.

\section{FINITE ELEMENT SIMULATION}

\subsection{Spot welding finite element model}

The use of shell and CBAR elements as discrete grids of the specimen and nugget are relatively accurate [19]; hence, the finite element model presented in this paper is established by both shell and CBAR elements to simulate the spot-welded specimens. It was observed in the experiment that the cracks of spot-welded specimens initiate from the heat-affected zone at the edge of the weld nugget and thereafter spread to the base metal area. Finally, the cracks directly penetrate the base metal $[20,28]$. 

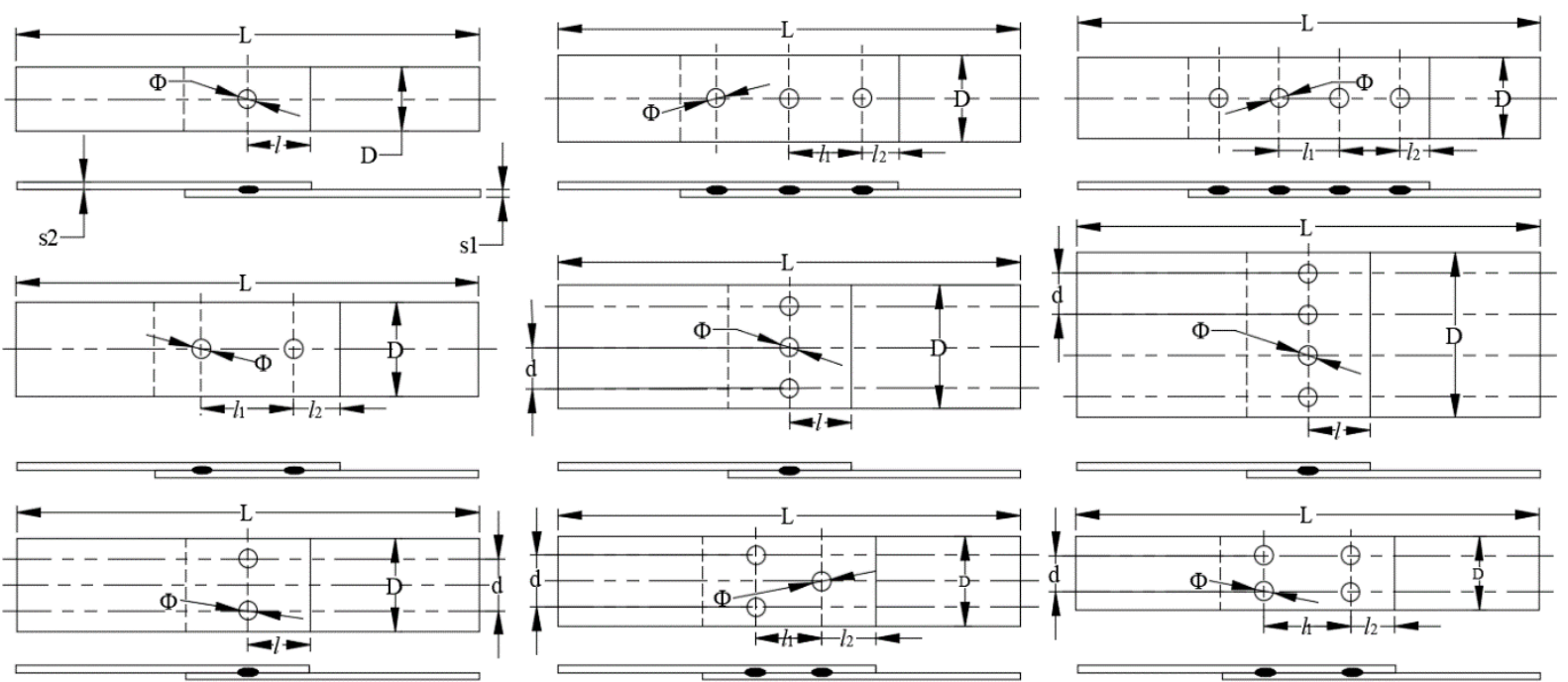

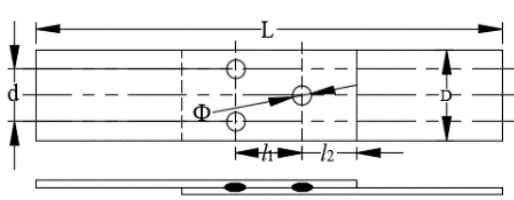

b) Three-spot welding

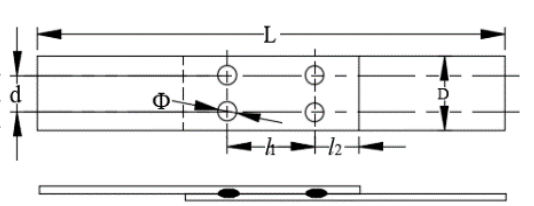

c) Four-spot welding

a) Single-spot and two-spot weldings

Figure 2: Diagrams of single-spot and multi-spot-welded specimens.

Comparing the crack position in the experiment with that in the simulation diagram under a 5-kN load (Fig. 3), it is found that the stress of the position where the crack is generated is the largest, and a severe stress concentration exists, resulting in low strength and proneness to fatigue damage.

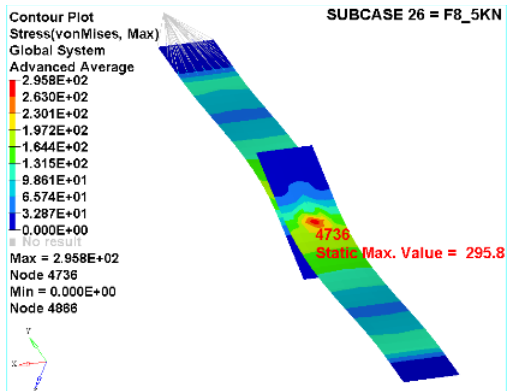

a) Single-spot welding

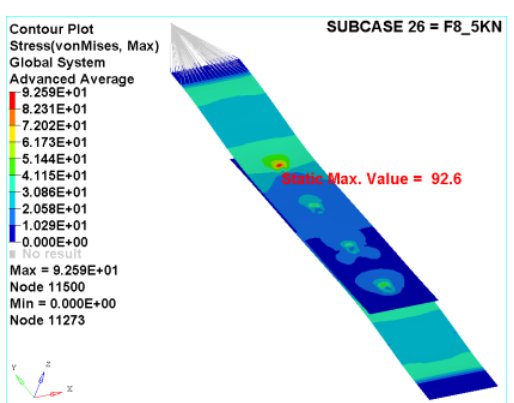

d) Longitudinal four-spot welding

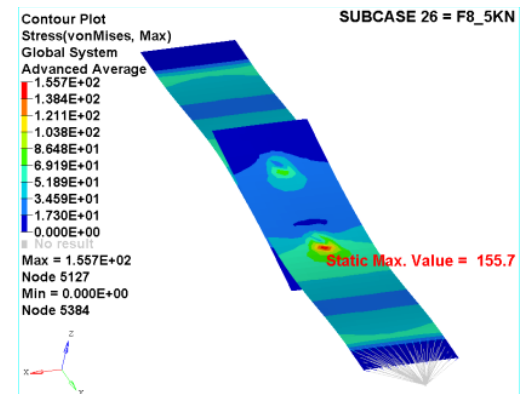

b) Longitudinal two-spot welding

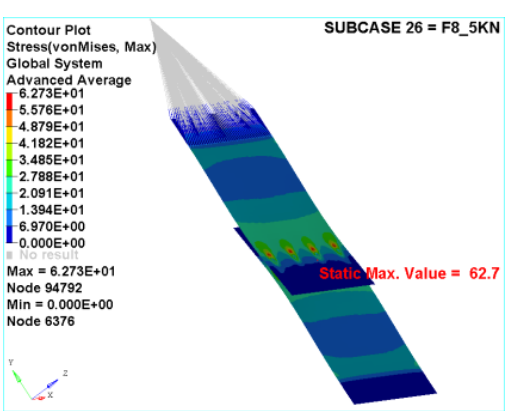

e) Transverse four-spot welding

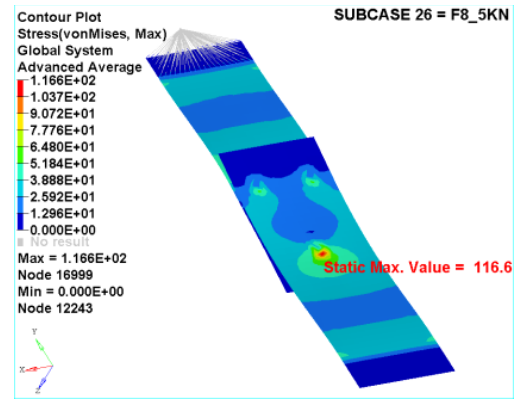

c) Triangular three-spot welding

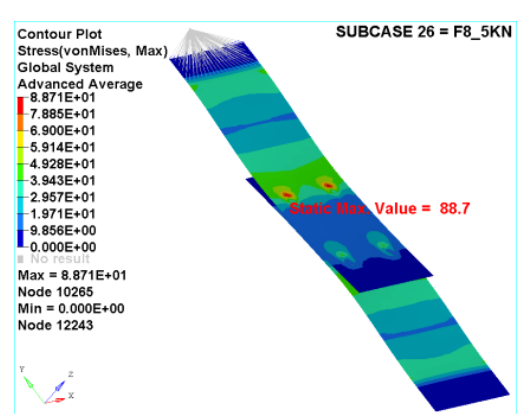

f) Double-row four-spot welding

Figure 3: Maximum stress positions in spot-welded specimens.

\subsection{Stress analysis}

The force analysis of the single-spot and multi-spot-welded specimens should be performed to analyse the problem of stress concentration in the crack initiation position. When the specimen is unloaded, the centrelines of the two plates are parallel; the distance between the two plates is denoted by $s$. After loading, a bending moment $(M)$ appears at the weld nugget under the action of the top and bottom forces. The moment $(M)$ forces the two plates to open at an angle $(\theta)$ so 
that the two centrelines are close to each other and tend to be the same line, as shown in Fig. 4. The force in plate A is shown in Fig. 5 [29].

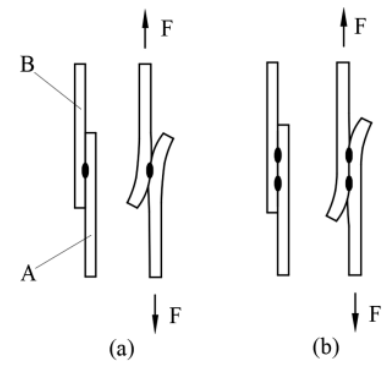

Figure 4: Stress analysis of single-spot and multi-spot-welded specimen.

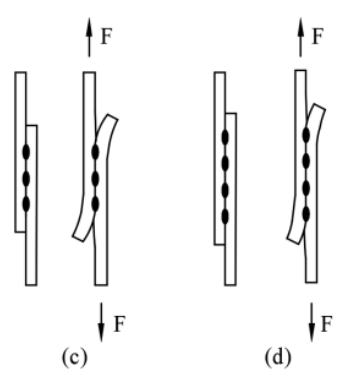

(d)
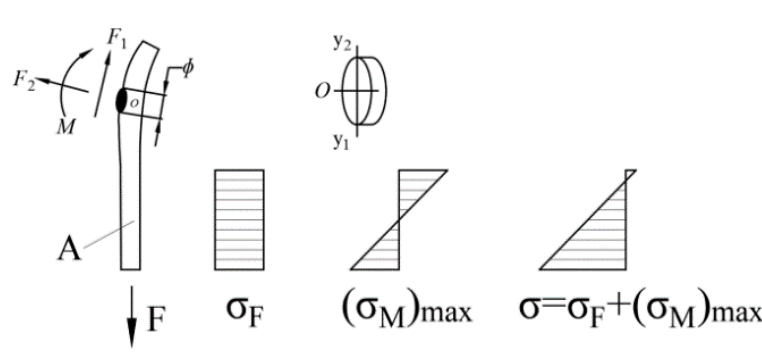

Figure 5: Force analysis of single-spot and multi-spot welding nuggets.

The shear stress is produced by $F_{1}$, whereas $F_{2}$ and $M$ produce the tensile stress at the weld nugget. According to the analysis of crack initiation and growth, the shear stress does not perform a major function. The main reason is that the superimposed tensile stresses of $\sigma_{F}$ and $\sigma_{M}$ generated by $F_{2}$ and $M$ result in the maximum stress at point $\mathrm{y}_{1}$ in plate A. The stress at point $\mathrm{y}_{2}$ in plate $\mathrm{B}$ is the maximum stress because of force symmetry and specimen structure. That is, the stress concentrations are most severe at point $\mathrm{y}_{1}$ in plate $\mathrm{A}$ and point $\mathrm{y}_{2}$ in plate $\mathrm{B}$, which are consistent with the results obtained by simulation and experiment. The comparison between simulation and theoretical maximum stresses of the single-spot-welded specimen with a thickness of $3 \mathrm{~mm}$ plus $3 \mathrm{~mm}$ and $8.7 \mathrm{~mm}$ (weld nugget diameter) is summarized in Table I. If the error of the simulation solution is within $10 \%$ of the error of the theoretical solution, the degree of approximation can be considered as relatively high. It can be observed that the error is within $10 \%$, which proves that the stress concentration position and stress value obtained by the simulation are accurate.

Table I: Stress comparison of simulation and theoretical solutions of stress concentration position of specimen.

\begin{tabular}{|c|c|c|c|c|c|c|}
\hline $\boldsymbol{F}(\mathrm{kN})$ & $\boldsymbol{\theta}(\mathrm{rad})$ & $\sigma_{F}(\mathrm{MPa})$ & $\sigma_{M}(\mathrm{MPa})$ & $\boldsymbol{\sigma}(\mathrm{MPa})$ & Simulation $(\mathrm{MPa})$ & Error $(\%)$ \\
\hline $\mathbf{1}$ & 0.146 & 4.90 & 46.40 & 51.31 & 56.17 & 9.48 \\
\hline $\mathbf{2}$ & 0.292 & 19.39 & 92.81 & 112.20 & 118.34 & 5.47 \\
\hline $\mathbf{3}$ & 0.438 & 42.86 & 139.21 & 182.07 & 177.50 & 2.51 \\
\hline $\mathbf{4}$ & 0.585 & 74.28 & 185.62 & 259.90 & 236.67 & 8.94 \\
\hline
\end{tabular}

\section{S-N CURVE FITTING}

The fatigue experimental results of all spot-welded specimens are differentiated according to the load ratios, plate thicknesses, and weld nugget diameters. The results are drawn as a $\Delta F-N$ scatter plot in Fig. 6. Among them, the referred fatigue life values of single-spot-welded specimens contain two groups: group 6 [28] and group 7 [12], and the referred fatigue life values of multi-spot-welded specimens are obtained from references [12-14, 19-28]. The loadlife $(\Delta F-N)$ curve is obtained by fitting the scatter value based on the least square method, and the square of the correlation coefficient $\left(R^{2}\right)$ is calculated. The closer $R^{2}$ is to 1 , the better the correlation of the fitting curve.

Fig. 6. shows that the overall dispersion of the data is large, and the $R^{2}$ values are less than 0.53 ; hence, the correlation is poor. For the specimens with different load ratios, plate thicknesses, and weld nugget diameters, the slope and intercept of the $\Delta F-N$ curves relatively differ, which indicates that the correlation between the load amplitude $(\Delta F)$ and fatigue life $(N)$ is considerably poor. At present, the $\Delta F-N$ curve is still used in engineering to predict the life 
of structures [19]. For structures with different plate thicknesses and weld nugget diameters, various $\Delta F-N$ curves are necessary to predict life. Because of the poor correlation of the $\Delta F-N$ curve, the acquisition process is time-consuming and laborious, and the curve selection process is cumbersome and complicated; the engineering requirements are thus not satisfied. It is therefore necessary to draw an S-N curve for spot welding with different plate thicknesses and weld nugget diameters that is more suitable for engineering applications.

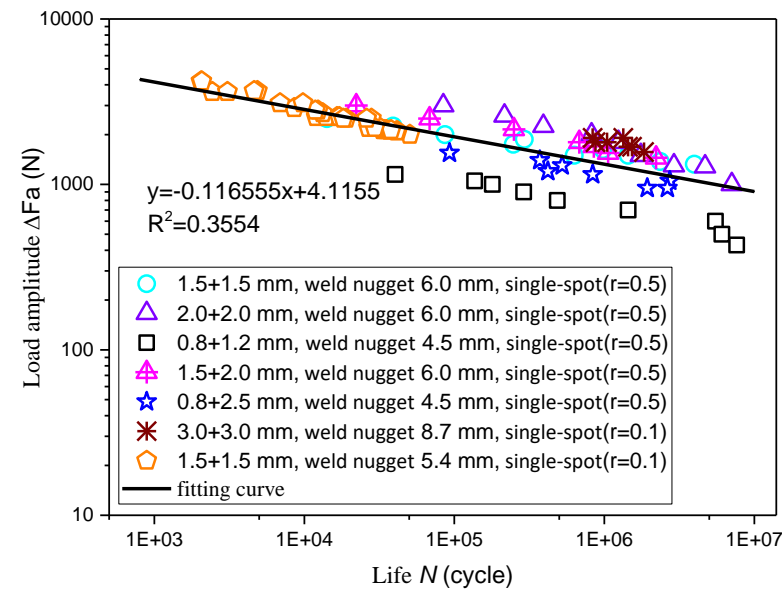

a) Single-spot welding

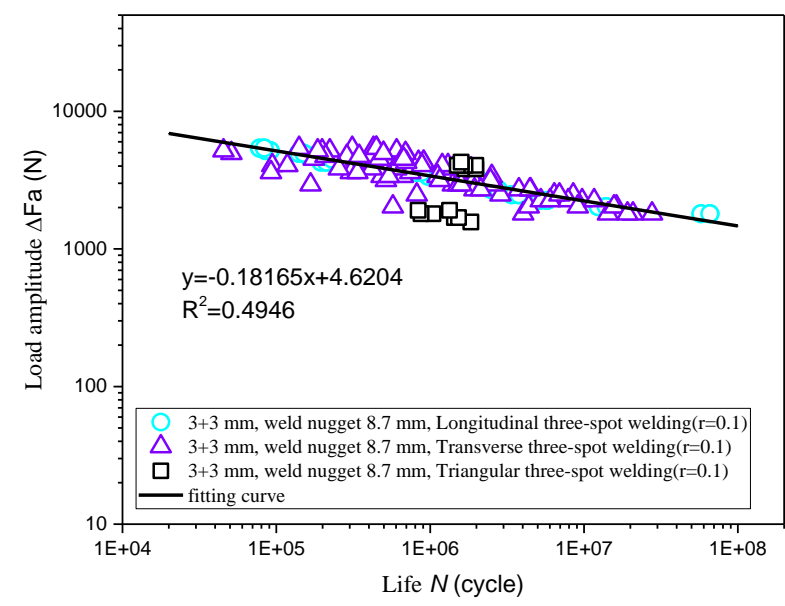

c) Three-spot welding

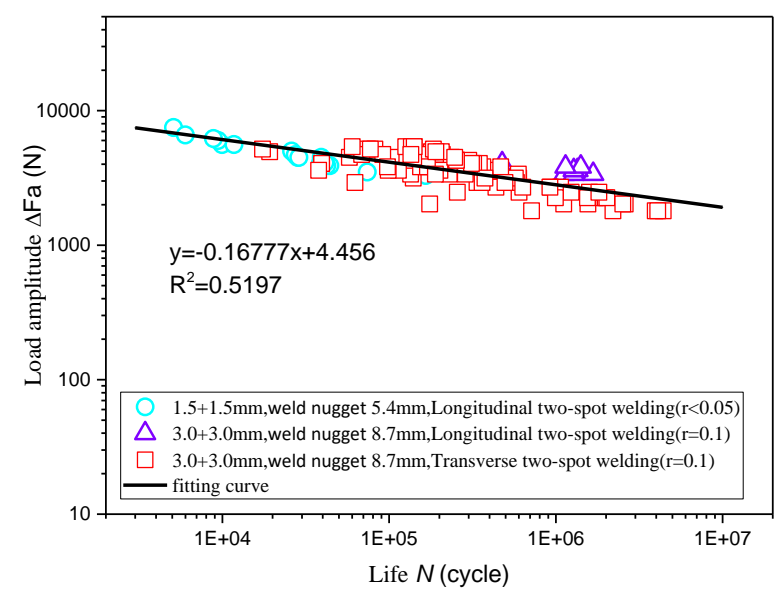

b) Two-spot welding

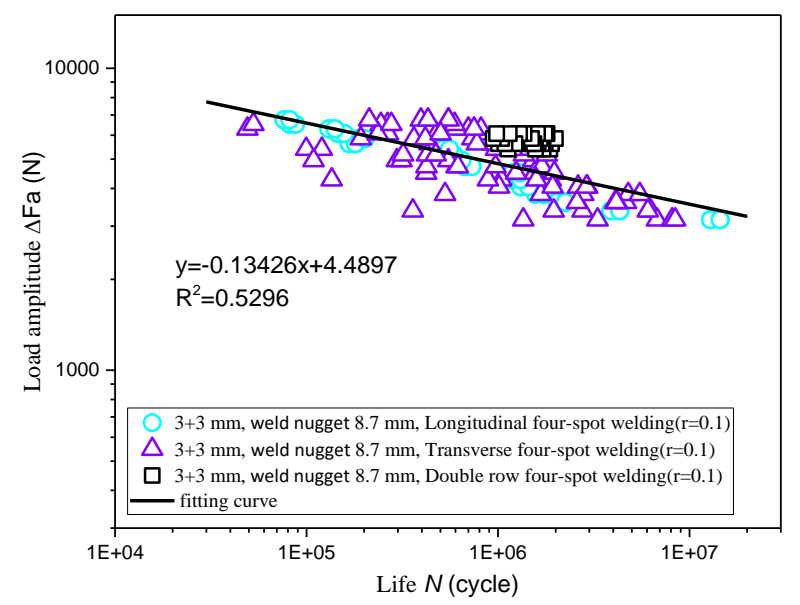

d) Four-spot welding

Figure 6: $\Delta F-N$ scatter plot of single-spot-welded specimens.

In the double logarithmic coordinate system, the experimental life $(N)$ of spot welding is taken as the abscissa, and the calculated corresponding equivalent structural stress range $(\Delta S)$ is the ordinate. Based on the least square method, the S-N curve of spot welding is obtained, as shown in Fig. 7 (equivalent structural stress range: $y-\lg \Delta S$; life: $x-\lg N$ ) [30]. Generally, the $\mathrm{S}$-N curve is evaluated in terms of the $\times 5$ scale band. If the data points fall within the $\times 5$ scale band, then the S-N curve is considered to be highly correlated [31-33]. Fig. 7 shows that most data points are located within the $\times 5$ scale band, and only few data points fall on the outer edge of these region. The $R^{2}$ values of the $\mathrm{S}-\mathrm{N}$ curves of the transverse four-spot welding and triangular three-spot welding are relatively small because of the specimens are few, whereas those of the others are greater than 0.6 . The $R^{2}$ values of the S-N curves of the longitudinally arranged multi-spot welding are greater than 0.95 , which proves that the prediction result of the spot welding S-N curve is good. 

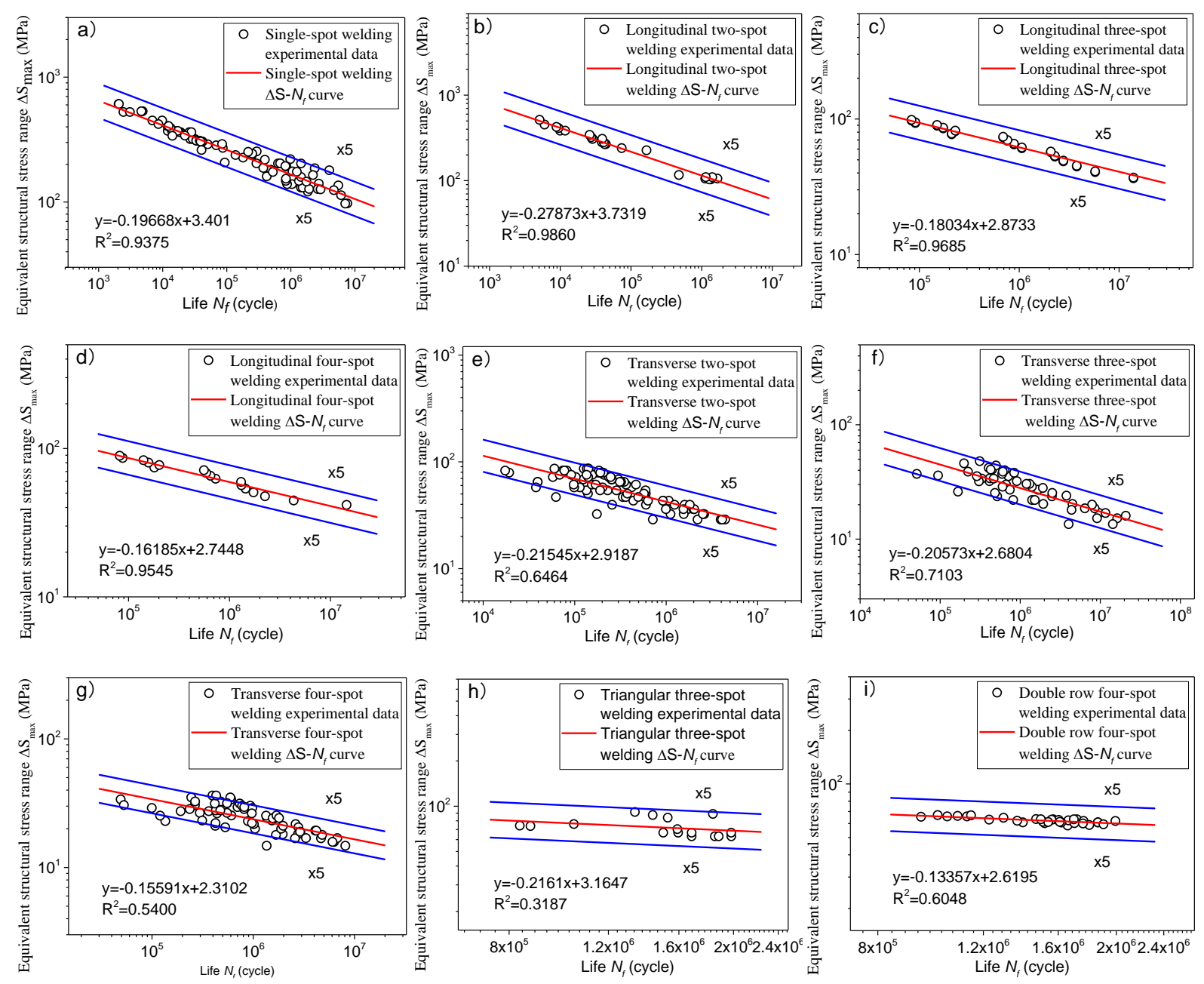

Figure 7: S-N curve of spot-welded specimens.

\section{STRUCTURAL STRESS OPTIMIZATION}

Because the $R^{2}$ values in Figs. 7 e to $7 \mathrm{i}$ are smaller than those in other $\mathrm{S}-\mathrm{N}$ curves, the structural stress formulas are optimized based on the quasi-Newton method (BFGS) to obtain more accurate structural stress and higher correlation S-N curve in this study. In the optimization procedure, $R^{2}$ is taken as the optimization target. The correction coefficients of the force, bending moment, weld nugget diameter $(d)$, plate thickness $(s)$, and plate width $(W)$ in Eqs. (1) to (4) are taken as variables [34]. The structural stress is corrected by three optimization methods $(\mathrm{C} 1, \mathrm{C} 2$ and $\mathrm{C} 3)$.

\subsection{Force and moment correction (C1)}

Based on the quasi-Newton method (BFGS), the force and moment in Eqs. (1) to (4) are corrected by introducing nine parameters. The structural stress formulas after introducing the correction parameters are expressed by Eqs. (6) to (8):

$$
\begin{gathered}
\sigma_{\max }(Q)=\frac{3 \Delta Q}{\pi s d} \times(\Delta Q)^{S F F X Y} \times D E F X Y \times T E F X Y \\
\sigma_{\max }(M)=\frac{6 \Delta M^{*}}{s^{2} W} \times\left(\Delta M^{*}\right)^{S F M X Y} \times D E M X Y \times T E M X Y \\
\sigma_{\max }(P)=\frac{\Delta P}{s^{2}} \times(\Delta P)^{S F F Z} \times D E F Z \times T E F Z
\end{gathered}
$$


The optimization results of the S-N curves are summarized in Table II. It can be observed that the $R^{2}$ values of the $\mathrm{S}-\mathrm{N}$ curves are slightly improved by $\mathrm{C} 1$ correction, and the correlation is better than that of the original $\mathrm{S}-\mathrm{N}$ curve.

\subsection{Weld nugget diameter, plate thickness, and plate width corrected altogether (C2)}

When the correction coefficients of the weld nugget diameter, plate thickness, and plate width are considered altogether, the structural stress formulae after introducing the correction parameters are shown in Eqs. (9) to (11):

$$
\begin{gathered}
\sigma_{\max }(Q)=\frac{3 \Delta Q}{\pi s d} \times S F F X Y \times d^{D E F X Y} \times s^{T E F X Y} \\
\sigma_{\max }(M)=\frac{6 \Delta M^{*}}{s^{2} W} \times S F M X Y \times s^{D E M X Y} \times W^{T E M X Y} \\
\sigma_{\max }(P)=\frac{\Delta P}{s^{2}} \times S F F Z \times d^{D E F Z} \times s^{T E F Z}
\end{gathered}
$$

Using the same method, the S-N curves of the spot-welded specimens with $R^{2}<0.9$ are optimized by introducing the nine correction parameters. The optimization results of the S-N curves are summarized in Table II. It can be observed that the $R^{2}$ values of the S-N curves are significantly improved by $\mathrm{C} 2$ correction, and the correlation is better than that of $\mathrm{C} 1$ correction.

\subsection{Correction of all factors (C3)}

The combination of $\mathrm{C} 1$ and $\mathrm{C} 2$ is used to correct all the influencing factors of the structural stress formulae. After introducing the correction parameters, these formulas can be expressed as Eqs. (12) to (14):

$$
\begin{gathered}
\sigma_{\max }(Q)=\frac{3 \Delta Q}{\pi s d} \times(\Delta Q)^{S F F X Y} \times d^{D E F X Y} \times s^{T E F X Y} \\
\sigma_{\max }(M)=\frac{6 \Delta M^{*}}{s^{2} W} \times\left(\Delta M^{*}\right)^{S F M X Y} \times s^{D E M X Y} \times W^{T E M X Y} \\
\sigma_{\max }(P)=\frac{\Delta P}{s^{2}} \times(\Delta P)^{S F F Z} \times d^{D E F Z} \times s^{T E F Z}
\end{gathered}
$$

Similarly, the S-N curves of the spot-welded specimens with $R^{2}<0.9$ are optimized by the nine correction parameters. The optimization results of the S-N curves are summarized in Table II. It can be observed that C3 correction has slightly increased the $R^{2}$ values of the S-N curves, and the correlation and correction effect are close to those of $\mathrm{C} 1$ correction.

Table II. Optimization results of S-N curves.

\begin{tabular}{|l|c|c|c|c|c|c|}
\hline \multirow{2}{*}{ Specimen types } & \multicolumn{2}{|c|}{ Correction C1 } & \multicolumn{2}{c|}{ Correction C2 } & \multicolumn{2}{c|}{ Correction C3 } \\
\cline { 2 - 7 } & $\boldsymbol{R}^{\mathbf{2}}$ & $\begin{array}{c}\text { Promotion } \\
\text { effect }\end{array}$ & $\boldsymbol{R}^{\mathbf{2}}$ & $\begin{array}{c}\text { Promotion } \\
\text { effect }\end{array}$ & $\boldsymbol{R}^{\mathbf{2}}$ & $\begin{array}{c}\text { Promotion } \\
\text { effect }\end{array}$ \\
\hline Transverse two-spot welding & 0.6478 & $0.22 \%$ & 0.6568 & $1.61 \%$ & 0.6489 & $0.39 \%$ \\
\hline Transverse three-spot welding & 0.7118 & $0.21 \%$ & 0.7414 & $4.38 \%$ & 0.7117 & $0.20 \%$ \\
\hline Transverse four-spot welding & 0.5521 & $2.24 \%$ & 0.5615 & $3.98 \%$ & 0.5524 & $2.30 \%$ \\
\hline Triangular three-spot welding & 0.3222 & $1.10 \%$ & 0.3622 & $13.65 \%$ & 0.3321 & $4.20 \%$ \\
\hline Double-row four-spot welding & 0.6162 & $1.88 \%$ & 0.6350 & $4.99 \%$ & 0.6083 & $0.58 \%$ \\
\hline
\end{tabular}

Compared with the three optimization results of the S-N curves of the spot-welded specimens, $\mathrm{C} 2$ is better, whereas $\mathrm{C} 1$ and $\mathrm{C} 3$ are not ideal. The main reason is that the structural stress formula is sensitive to the weld nugget diameter, plate thickness, and plate width; hence, the effect of $\mathrm{C} 2$ correction is evident. The $\mathrm{C} 1$ and $\mathrm{C} 3$ corrections are more suitable for correcting $\mathrm{S}-\mathrm{N}$ curves with more experimental data. However, the amount of experimental data in this study is limited, which makes the two correction methods less effective. 


\subsection{Quantitative relationship between single-spot and multi-spot-welded specimens}

Through experiment and simulation, the S-N curves of single-spot and multi-spot-welded specimens are obtained and S-N curves with a lower correlation coefficient are optimized based on the quasi-Newton method. The final S-N curves of the spot-welded specimens are summarized in Table III.

Table III. Final S-N curve of spot-welded specimens.

\begin{tabular}{|l|c|c|c|c|c|}
\hline \multirow{2}{*}{\multicolumn{1}{|c|}{ Specimen types }} & \multicolumn{4}{c|}{ S-N curve $(\boldsymbol{y}=\boldsymbol{a x}+\boldsymbol{b})$} & \multirow{2}{*}{$\boldsymbol{R}^{\mathbf{2}}$} \\
\cline { 2 - 5 } & $\boldsymbol{a}$ & Value $(\boldsymbol{a})$ & $\boldsymbol{b}$ & Value $(\boldsymbol{b})$ & \\
\hline Single-spot welding & $a_{S}$ & -0.19668 & $b_{S}$ & 3.401 & 0.9375 \\
\hline Longitudinal two-spot welding & $a_{2 L}$ & -0.27873 & $b_{2 L}$ & 3.7319 & 0.9860 \\
\hline Longitudinal three-spot welding & $a_{3 L}$ & -0.18034 & $b_{3 L}$ & 2.8733 & 0.9685 \\
\hline Longitudinal four-spot welding & $a_{4 L}$ & -0.16185 & $b_{4 L}$ & 2.7448 & 0.9545 \\
\hline Transverse two-spot welding & $a_{2 T}$ & -0.21546 & $b_{2 T}$ & 4.4086 & 0.6568 \\
\hline Transverse three-spot welding & $a_{3 T}$ & -0.20412 & $b_{3 T}$ & 2.8361 & 0.7414 \\
\hline Transverse four-spot welding & $a_{4 T}$ & -0.15264 & $b_{4 T}$ & 2.6841 & 0.5615 \\
\hline Triangular three-spot welding & $a_{3 i}$ & -0.25882 & $b_{3 i}$ & 3.7139 & 0.6796 \\
\hline Double-row four-spot welding & $a_{4 D}$ & -0.17196 & $b_{4 D}$ & 3.2064 & 0.8859 \\
\hline
\end{tabular}

Through the S-N curve equations of single-spot and multi-spot weldings, the quantitative relationship of life among spot welding with different solder joints can be obtained when the corresponding structural stress remains the same. Similarly, the quantitative relationship of the corresponding structural stresses among spot welding with different solder joints can be obtained when the life remains the same, as shown in Eq. (15):

$$
\left\{\begin{array}{c}
N_{2 L}=\frac{a_{S}}{a_{2 L}} N_{S}+\frac{b_{S}-b_{2 L}}{a_{2 L}} \\
N_{3 L}=\frac{a_{2 L}}{a_{3 L}} N_{2 L}+\frac{b_{2 L}-b_{3 L}}{a_{3 L}} \\
\sigma_{2 L}=\frac{a_{2 L}}{a_{S}} \sigma_{S}-\frac{a_{2 L} b_{S}}{a_{S}}+b_{2 L} \\
\sigma_{3 L}=\frac{a_{3 L}}{a_{2 T}} \sigma_{2 T}-\frac{a_{3 L} b_{2 T}}{a_{2 T}}+b_{3 L} \\
\ldots \ldots
\end{array}\right.
$$

By extracting the coefficients of S-N curve equations of the single-spot and multi-spot weldings, the relationship curve between the number of solder joints and slope of S-N curves and that between the number of solder joints and intercept of S-N curves are shown in Fig. 8.

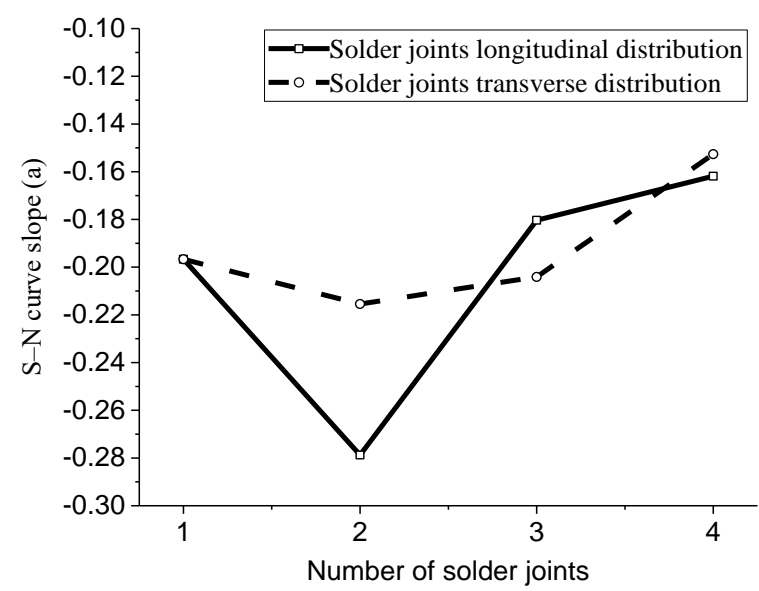

a) Relationship curve between solder joints and a

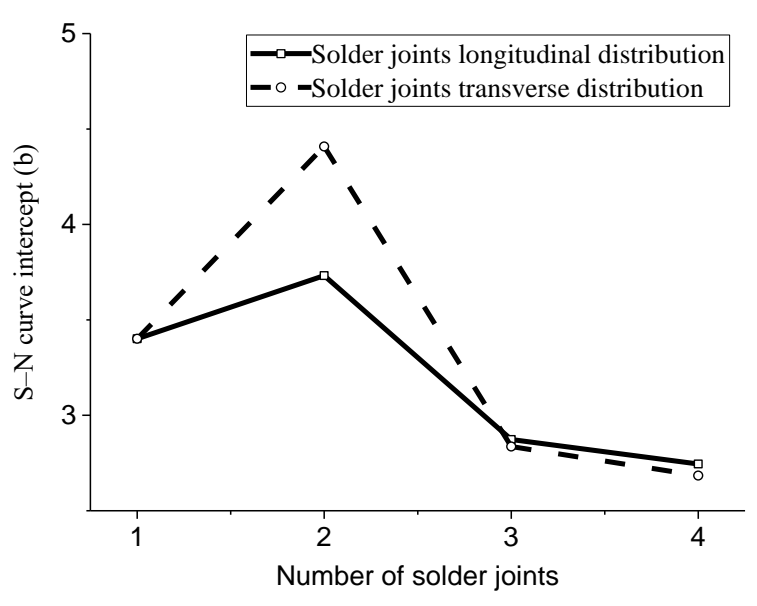

b) Relationship curve between solder joints and b

Figure 8: Quantitative relationship between single-spot and multi-spot weldings. 
It is observed that as the number of solder joints increases, the absolute values of the slope and intercept of the S-N curves first increase and thereafter decrease. After the absolute values of the slope and the intercept have reached the maximum at the two solder joints, both absolute values gradually decrease with the increase in the number of solder joints. The reason is that the higher the number of solder joints, the larger the allowable load of the specimens at the same life level, and the longer the life of the specimens at the same load level. Through the relationship curves shown in Fig. 8, the S-N curves of various spot-welded specimens can be directly obtained; this provides theoretical support for the life prediction of multi-spot welding. It is simple, easy to use, and has engineering significance.

\section{CONCLUSION}

In this investigation, through experiment and finite element simulation of spot welding, the S-N curves of single-spot and multi-spot-welded specimens are studied based on the structural stress method, and the quantitative relationship between $\mathrm{S}-\mathrm{N}$ curves with different numbers of solder joints is deduced. Based on the results obtained, the following conclusions can be drawn:

1) It is found that the stress concentration exists at the crack initiation position of spotwelded specimens. The main reason is that there is a large tensile stress at the weld nugget.

2) Most data points of the S-N curves of single-spot and multi-spot weldings fall within the $\times 5$ scale band, indicating a good correlation. To improve the fitting effect of S-N curves with relatively lower correlation coefficients, the structural stress formulae are optimized based on the quasi-Newton method (BFGS). The correlation coefficients of the optimized S-N curves have a certain improvement. The $\mathrm{C} 2$ correction exhibits the best effect because the structural stress formula is sensitive to the weld nugget diameter, plate thickness, and plate width.

3) The quantitative relationship among S-N curves with different numbers of solder joints is deduced by S-N curve equations. The relationship curve between the number of solder joints and slope of the S-N curve and that between the number of solder joints and intercept of the $\mathrm{S}-\mathrm{N}$ curve are determined. The foregoing can provide reference for the life prediction of multispot welding and has more engineering significance.

In this study, the calculation method of the quantitative relationship of spot welding between life, equivalent structural stress and S-N curve of spot welding with different numbers of solder joints is provided. However, due to the limitation of test conditions and amount of test data; the exact solution cannot be obtained. Supplementary experiments are necessary for further improvement.

\section{ACKNOWLEDGEMENT}

This work was supported by the Union Project of National Natural Science Foundation of China (No. U1534209) and by the National Natural Science Foundation of China (No. 51675446).

\section{REFERENCES}

[1] Liu, X. F. (2014). Cumulative Fatigue Damage and Life Analysis of Tensile-Shear Spot-Welded Joints, Master Thesis, Kunming University of Science and Technology, Kunming (in Chinese)

[2] Sun, L.; Zhu, Z.; Chen, N.; Sun, Q.; Zhang, B. (2000). Characteristics and modeling method of the spot welding connection interface of auto body sheet metal parts, Automotive Engineering, Vol. 2000, No. 1, 69-72, doi:10.19562/j.chinasae.qcgc.2000.01.018

[3] Duan, B.; Wang, J. C.; Lu, Z. H.; Zhang, G. X.; Zhang, C. H. (2018). Parameter analysis and optimization of the rotating arc NG-GMAW welding process, International Journal of Simulation Modelling, Vol. 17, No. 1, 170-179, doi:10.2507/IJSIMM17(1)CO4 
[4] Sheppard, S. D. (1993). Estimation of fatigue propagation life in resistance spot welds, Mitchell, M.; Landgraf, R. (Eds.), Advances in Fatigue Lifetime Predictive Techniques, $2^{\text {nd }}$ edition, ASTM International, West Conshohocken, 169-185, doi:10.1520/STP15085S

[5] Sheppard, S. D. (1996). Further refinement of a methodology for fatigue life estimation in resistance spot weld connections, Mitchell, M.; Landgraf, R. (Eds.), Advances in Fatigue Lifetime Predictive Techniques, $3^{\text {rd }}$ edition, ASTM International, West Conshohocken, 265-282, doi:10.1520/STP14142S

[6] Rupp, A.; Klaus, S.; Grubisic, V. (1995). Computer aided dimensioning of spot-welded automotive structures, SAE Technical Paper, Paper 950711, 13 pages, doi:10.4271/950711

[7] Swellam, M. H.; Kurath, P.; Lawrence, F. V. (1992). Electric-potential-drop studies of fatigue crack development in tensile-shear spot welds, Mitchell, M.; Landgraf, R. (Eds.), Advances in Fatigue Lifetime Predictive Techniques, ASTM International, West Conshohocken, 383-401, doi:10.1520/STP24170S

[8] Swellam, M. H.; Ban As, G.; Lawrence, F. V. (1994). A fatigue design parameter for spot welds, Fatigue \& Fracture of Engineering Materials \& Structures, Vol. 17, No. 10, 1197-1204, doi:10.1111/j.1460-2695.1994.tb01408.x

[9] Kang, H. T. (2007). Fatigue prediction of spot welded joints using equivalent structural stress, Materials \& Design, Vol. 28, No. 3, 837-843, doi:10.1016/j.matdes.2005.11.001

[10] Pan, N.; Sheppard, S. D. (2002). Spot welds fatigue life prediction with cyclic strain range, International Journal of Fatigue, Vol. 24, No. 5, 519-528, doi:10.1016/S0142-1123(01)00157-8

[11] Lee, H.; Choi, J. (2005). Overload analysis and fatigue life prediction of spot-welded specimens using an effective J-integral, Mechanics of Materials, Vol. 37, No. 1, 19-32, doi:10.1016/ j.mechmat.2003.12.006

[12] Yang, Y. N. (2016). Fatigue Life Prediction of Tension-Shear Spot Weld Specimen Based on BP Neural Network, Master Thesis, Kunming University of Science and Technology, Kunming (in Chinese)

[13] Li, L. S. (2007). Study on Fatigue Damage and Life Prediction Based on Dynamic Response Frequency for Double-Spot Weld Joints, Master Thesis, Beijing University of Technology, Beijing (in Chinese)

[14] Wang, R.-J.; Shang, D.-G.; Li, L.-S.; Li, C.-S.; Yan, C.-L. (2007). Fatigue life prediction of spot welds based on change of natural frequency, Journal of Beijing University of Technology, Vol. 33, No. 12, 1252-1256, doi:10.3969/j.issn.0254-0037.2007.12.004

[15] Kang, H.; Barkey, M. E.; Lee, Y. (2000). Evaluation of multiaxial spot weld fatigue parameters for proportional loading, International Journal of Fatigue, Vol. 22, No. 8, 691-702, doi:10.1016/ $\underline{\mathrm{S} 0142-1123(00) 00037-2}$

[16] Radaj, D.; Zhang, S. (1991). Stress intensity factors for spot welds between plates of unequal thickness, Engineering Fracture Mechanics, Vol. 39, No. 2, 391-413, doi:10.1016/00137944(91)90053-4

[17] Liu, J. (2015). Research on Quantitative and Intelligent Ultrasonic Detection for Resistance Spot Welding of Stainless Steel, PhD Thesis, Jilin University, Changchun (in Chinese)

[18] Professional Committee of Welding Society of China, Mechanical Engineering Society (1994). Resistance Welding Theory and Practice, Mechanical Industry Press, Beijing (in Chinese)

[19] Wang, F. (2018). Research on Equivalent Stress Method of Spot Welding and Ring Welding, Master Thesis, Southwest Jiaotong University, Chengdu (in Chinese)

[20] Esmaeili, F.; Rahmani, A.; Barzegar, S.; Afkar, A. (2015). Prediction of fatigue life for multi-spot welded joints with different arrangements using different multiaxial fatigue criteria, Materials \& Design, Vol. 72, 21-30, doi:10.1016/j.matdes.2015.02.008

[21] Wang, R.-J.; Shang, D.-G.; Li, L.-S.; Li, C.-S. (2007). Frequency change of tension-shear two spot welds during fatigue, Laboratory Research and Exploration, Vol. 2007, No. 11, 247-250

[22] Wang, R. J. (2008). Fatigue Damage and Life Prediction Based on Dynamic Response Analysis for Spot-Welded Joints, PhD Thesis, Beijing University of Technology, Beijing (in Chinese)

[23] Lee, H.; Kim, N. (2004). Fatigue life prediction of multi-spot-welded panel structures using an equivalent stress intensity factor, International Journal of Fatigue, Vol. 26, No. 4, 403-412, doi:10.1016/j.ijfatigue.2003.07.001 
[24] Kang, H.; Barkey, M. E.; Lee, Y. (2000). Evaluation of multiaxial spot weld fatigue parameters for proportional loading, International Journal of Fatigue, Vol. 22, No. 8, 691-702, doi:10.1016/S0142-1123(00)00037-2

[25] Atherton, H.; Xia, Y.; Kamalu, J. (2017). The mechanical properties and geometrical configuration efficiency of multiple resistance spot welds, Advances in Materials and Processing Technologies, Vol. 3, No. 3, 449-462, doi:10.1080/2374068x.2017.1338880

[26] Salvini, P.; Vivio, F.; Vullo, V. (2009). Fatigue life evaluation for multi-spot welded structures, International Journal of Fatigue, Vol. 31, No. 1, 122-129, doi:10.1016/j.ijfatigue.2008.06.006

[27] Adib, H.; Gilgert, J.; Pluvinage, G. (2004). Fatigue life duration prediction for welded spots by volumetric method, International Journal of Fatigue, Vol. 26, No. 1, 81-94, doi:10.1016/S0142$1123(03) 00068-9$

[28] Wang, R. (2010). The Experimental Study of Structural Strength and Fatigue Reliability of Multiple-Spot Welding of Cold-Rolled Austenitic Stainless Steel, Master Thesis, Beijing Jiaotong University, Beijing, doi:10.7666/d.y1781203

[29] Radaj, D. (1994). Fatigue Strength of Welded Structures, Machinery Industry Press, Beijing (in Chinese, translated by Zheng, C.-Y. et al.)

[30] Yang, L.; Yang, B.; Yang, G.; Xiao, S.; Zhu, T.; Wang, F. (2020). A comparative study of fatigue estimation methods for single-spot and multi-spot welds, Fatigue \& Fracture of Engineering Materials \& Structures, Vol. 43, No. 6, 1142-1158, doi:10.1111/ffe.13185

[31] Zamani, P.; Farhangdoost, K. (2020). On the Influence of riveting process parameters on fatigue life of riveted lap joint, Journal of Applied and Computational Mechanics, Vol. 6, No. 2, 248-258, doi:10.22055/jacm.2019.28827.1507

[32] Chen, C. Y. (2002). Fatigue and Fracture, Huazhong University of Science and Technology Press Co. Ltd., Wuhan (in Chinese)

[33] Zhao, J. (2019). Modelling of crack growth using a new fracture criteria based peridynamics, Journal of Applied and Computational Mechanics, Vol. 5, No. 3, 498-516, doi:10.22055/ jacm.2017.23515.1160

[34] Kang, H.; Wu, X.; Khosrovaneh, A. K.; Li, Z. (2017). Data processing procedure for fatigue life prediction of spot-welded joints using a structural stress method, Wei, Z.; Nikbin, K.; McKeighan, P.; Harlow, D. (Eds.), Fatigue and Fracture Test Planning, Test Data Acquisitions and Analysis, West Conshohocken, 198-211, doi:10.1520/STP159820160054 